\title{
Comparisons of Science, Technology, Engineering, and Mathematics (STEM) Education Reform
}

\author{
Keiichiro Yoshinaga \\ Institute of Liberal Arts and Science \\ Kanazawa University \\ JAPAN \\ yoshinaga@staff.kanazawa-u.ac.jp
}

\begin{abstract}
This paper discusses the rise of Science, Technology, Engineering, and Mathematics (STEM) education reform in the United States and Asia. As shown in the results of international tests such as PISA and TIMMS, secondary school students in Asia do better than their counterparts in the U.S. Nevertheless, it is also true that U.S. universities, particularly graduate schools have more strengths than Asian universities. The rise of the knowledge society is raising a demand for STEM workforce, and its solid production is becoming imperative in each region for the pursuit of economic development. The paper picks up active learning as a new culture of education regardless of their educational differences. It argues that it is a great means not only to reform STEM education but also to create innovation.
\end{abstract}

Keywords-STEM Education Reform; Secondary Education; Engagment; Active Learning; Innovation; Technology Enhanced Learning; Knowledge Society

\section{INTRODUCTION}

Today many countries are working on Science, Technology, Engineering, and Mathematics (STEM) education reform from secondary to postgraduate level. In the United States, Association of American Colleges and Universities (AAC\&U) has worked on "Project Kaleidoscope" since 1989. Association of American Universities (AAU) launched "Undergraduate STEM Education Initiative" in 2011. Japan has supported STEM education reform with "Super Science High Schools" at secondary level since 2002, "Support Program for Distinguished University Education" at undergraduate level started in 2008. "Program for Leading Graduate Schools" at postgraduate level began in 2011. China started "Science Education Reform and Practice Program" in 2005 and has particularly focused on the training of talented students with "Science and Engineering Special Programs." University of Science and Technology of China and South University of Science and Technology of China are noteworthy for their programs for the gifted youth.

Such an attention to the STEM is inseparable from the rise of the knowledge society and the Fourth Industrial Revolution, that are replacing mass production and physical labor with digital information and creative design. The STEM is considered to be the essential part of the knowledge society and the engine of economic development [1]. Knowledge society also accompanies the mobility of STEM talents. Many countries are trying to attract STEM talents with incentives as well as nurturing domestic talents with educational reform [2][3].

This paper is a presentation of the result of literature reviews of STEM education reform and of the site visits made to the U.S. and Asia for the past five years. The production of STEM workforce and the improvement of STEM education have been discussed for a long time, but faculty members have struggled to improve teaching. Now the introduction of active learning seems to give an answer to the issue and is accelerating educational reforms.

\section{CASE OF THE U.S.}

\section{A. Issues}

If we take a close look at the situation of STEM education in the U.S., it has three particular issues. The first issue is the shortage of STEM workforce [4]. Corresponding to the rise of the knowledge society, STEM-related jobs are expanding. According to one estimate, between 2010 and 2020, two million new STEM-related jobs will be created [5]. Fields such as AI, Big Data, Drone, Cyber Security, Self-Driving, and Fintech require STEM knowledge.

The shortage comes from both the retirement of babyboomers and the short supply of STEM graduates. Whereas more than $40 \%$ of undergraduates receive STEM degrees in China, South Korea, and Taiwan, the proportion in the U.S. is about $30 \%$ (Table 1) [6]. This is related to the low retention of intended STEM majors. According to the survey of them in 2009 , only $63.3 \%$ of them obtained STEM degrees in five years [7]. This comes from the fact that STEM education at the secondary level has a serious defect and large introductory courses at universities do not provide enough support for freshmen [8][9].

The second issue is the heavy reliance on foreign talents. In $2011,36 \%$ of S\&E doctorates in the U.S. were conferred to international students [10]. Although the U.S. universities and industries have benefitted from the import of them, their future 
supply is uncertain because of the talent competition with Asian countries and the U.S. immigration policy [11].

The third issue is a skill gap between university education and workplace [12]. It has been pointed out that the university focuses on the input of expertise in a particular field, whereas Table 1 S\&E Ratio

\begin{tabular}{|l|c|c|c|}
\hline & College Grads & S\&E Grads & S\&E Ratio \\
\hline China & $2,590,535$ & $1,288,999$ & $49.8 \%$ \\
\hline India & $2,052,197$ & 463,186 & $22.6 \%$ \\
\hline U.S. & $1,668,227$ & 525,374 & $31.5 \%$ \\
\hline Japan & 564,035 & 176,753 & $31.3 \%$ \\
\hline South Korea & 308,162 & 123,658 & $40.1 \%$ \\
\hline Taiwan & 227,174 & 88,294 & $38.9 \%$ \\
\hline
\end{tabular}

transferrable skills such as communication, teamwork, and independent thinking are required in workplace. Responding to the rise of the knowledge society, skills that industry demands from the university education are changing. Today industry is calling for more adaptability, creativity, and entrepreneurship from workers [13].

\section{B. STEM Reforms}

To tackle the issues of STEM education, AAU's "Undergraduate STEM Education Initiative" works on active learning, faculty development, institutional research, and introductory course reform. All of the 8 pilot universities are involved in active learning. Active learning includes the transformation of lectures to exercises, online delivery of lectures (flipped classroom), group work, peer instruction, and facilitation instead of teaching. One characteristic of active learning in the U.S. is that it is considered to give students motivation, study habit, study skills, and even remedial skills [14].

Most pilot universities also focus on the reform of introductory STEM courses because they are great hurdles for freshmen. Not only the large lecture halls holding up to 200 or 300 students but also the curriculum which is often the collection of isolated topics and the algorithmic problem solving without conceptual understanding are intimidating to students [15]. Therefore, STEM education reform involves organizational efforts as well as individual ones. Departmental agreement on curriculum structure and teaching arrangement, and institutional supports for infrastructure and staffing are necessary. This is the reason why faculty development is necessary at every level of management in the university.

Another characteristic of the Initiative is institutional research. Educational reform should be based on solid evidence [16]. Although one meta-analysis of the performance of active learning suggests the $6 \%$ gain [17], many more issues have to be identified to make active learning effective.

Along with the AAU project, Massachusetts Institute of Technology (MIT) Future Plan which was released in 2014 is a great example of where STEM education is heading for [18]. The Plan advocates the use of online lectures, the emphasis on communication skills, the breakup of the unit system into smaller modules, the blend of classroom and online activities, and the connection between technology and social responsibility.

Some of the ideas proposed in the MIT Future Plan have been implemented in smaller engineering colleges such as Olin College, Harvey Mudd College, and Rose-Hulman Institute of Technology. For example, Olin College minimizes the transmission of knowledge as much as possible and encourages students to learn by themselves through projects. When the author visited Olin College and interviewed students, one comment made by one student was impressive. $\mathrm{He}$ said, "Our engineering knowledge may be limited compared to other universities. We are good at finding problems first and acquiring necessary knowledge and skills later." Innovative universities such as MIT, Stanford, Duke are members of the international organization, Conceive Design Implement Operate (CDIO) which advocates design, professional skills, and projects in engineering education.

\section{CASE IN ASIA}

\section{A. Issues}

As shown in their high performance in international tests such as PISA and TIMMS, East Asians are well-known for their excellence in STEM subjects (Table 2). This is because of the Confucian tradition which nurtures the respect for learning, hard work, and high achievements. The tradition also creates a pressure to enter a selective university because its hierarchical view selects people with the rank of the university they graduated. Therefore, university entrance examinations play a significant role to force students to study hard.

The flip side of the excessive attention to entrance examinations is the lack of engagement among students. In spite of their high performance in PISA and TIMMS, students in Japan, Taiwan, and South Korea do not like studying math and science [19]. They often lack scientific curiosity or internal motivation. Once they enter a university, some of them lose interest in the study. This a serious defect of education in Asia and is particularly harmful to produce innovation in engineering.

The puzzling state of STEM education in Asia is well discussed in English, STEM: Country Comparisons [20]. According to the report, Chinese university students complain that they are taught in a similar way with secondary schools and that professors are authoritative and lack the flexibility to appreciate students' originality. In South Korea, social prestige is given to governmental officials and medical doctors rather than engineers. In Japan, high school students give up STEM subjects at an early stage. In Taiwan, science is considered to be the acceptance of facts, and experiment and inference are not taught enough.

\section{B. Reforms}

To solve the issues of the STEM, Asian countries are actively working on reforms. They are entrance examination reform, teaching reform, undergraduate education reform, and 
student support. Many universities are now adopting holistic entrance assessment which takes high school records, extracurricular activities, interviews, and essays into consideration instead of paper test scores. They are also converting old lecture halls to active learning studios for group work,

Table 2 Asian Excellence in STEM

\begin{tabular}{|l|l|l|l|l|l|}
\hline & \multicolumn{2}{|c|}{ PISA(Math) } & PISA(Sci) & TIMSS(Math) & TIMSS(Sci) \\
\hline & \multicolumn{2}{|c|}{ Age15 (2012) } & \multicolumn{2}{c|}{$8^{\text {th }}$ Grade (2011) } \\
\hline 1 & Shanghai & Shanghai & South Korea & Singapore \\
\hline 2 & Singapore & $\begin{array}{l}\text { Hong } \\
\text { Kong }\end{array}$ & Singapore & Taiwan \\
\hline 3 & Hong Kong & Singapore & Taiwan & South Korea \\
\hline 4 & Taipei & Japan & Hong Kong & Russia \\
\hline 5 & South Korea & Finland & Japan & \\
\hline
\end{tabular}

discussion, and presentation. Active learning often accompanies technology which makes flipped classroom and online exercises possible to secure more time for classroom activities. Some countries are introducing liberal arts education to pursue the width of education and are strengthening academic support. The most impressive example of educational reform is the Hive in Nanyang Technological University in Singapore where the whole building was designed for active learning. As a city-state, Singapore seems to be the frontrunner of higher education reform not only in Asia but also in the world.

\section{HIGHER EDUCATION AND KNOWLEDGE SOCIETY}

Knowledge society or the Fourth Industrial Revolution fundamentally transforms higher education. There are two characteristics in this transformation. One is the importance of transferrable skills and the other is that of lifelong learning. Today knowledge and skills are outdated at a remarkable speed. Transferrable skills are more critical than the concentration in one expertise. Particularly important is the skill to learn new things at every stage of life.

In the knowledge society, the concept of ability is expanded. In the past, the ability was mainly developed for knowledge and understanding, but today the concept of ability is multiple, as Howard Gardner adds bodily intelligence and interpersonal intelligence to academic intelligence (Table 3) [21]. Since the ability includes curiosity, motivation, expression, engagement, and leadership, higher education has to be aligned with a new situation.

To cope with this situation, a new culture of learning is necessary [22]. Knowledge transfer should be replaced by knowledge construction, prohibition by encouragement, orders

\begin{tabular}{|l|c|}
\hline Spatial & \multirow{2}{*}{ Artistic Intelligence } \\
\cline { 1 - 1 } Bodily-kinesthetic & Persuasion, \\
Musical & Management \\
\hline Interpersonal & \\
\hline Intrapersonal &
\end{tabular}

Table 4 A New Culture of Learning

\begin{tabular}{|l|l|}
\hline Traditional & New \\
\hline Knowledge Transfer & Construct Knowlege \\
\hline "Can't Do" & "Can Do" \\
\hline Follow Orders & Follow Your Passion \\
\hline Learn in Class & Learn $24 \times 7$ \\
\hline Learn Along & Learn in Teams \\
\hline Problem-based & Design-based \\
\hline
\end{tabular}

by passion, classroom by online, solitary learning by team learning, and problem-based learning by design-based learning (Table 4).

Teresa Amabile lists the three elements of creativity (Fig.1) [23]. They are expertise, motivation, and creative-thinking skills. STEM education has focused on expertise, less motivation, and creative thinking skills. Project-based learning at institutions such as Olin College are keen to this theory and are trying to strike a balance among expertise, motivation, and creative thinking skills. Internal motivation urges students to master expertise, not the other way round. Creative thinking skills mainly deal with teamwork and communication, both of which are important for organized knowledge.

Asian countries in general lag behind the U.S. in creative thinking skills. To be creative, Asian universities should pay more attention to students' development with encouragement and support. Former MIT President of MIT, Charles Vest said the following. "Making universities and engineering schools exiting, creative, adventurous, rigorous, demanding, and empowering milieus is more important than specifying curricular details."

Innovation goes beyond the boundary of engineering. According to Tim Brown, the three elements of innovation are feasibility, viability, and desirability (Fig.2) [24]. They correspond to engineering, business, and artistic skills in this order.

To produce innovation, market needs, business models, and artistic sense should be integrated into the engineering curriculum. Therefore, it is no coincident that institutions established for innovation such as Stanford d school, MIT Media Lab, and Kaospilot in Denmark emphasize the fusion of engineering, business, and art.

Table 3 Multiple Intelligences

\begin{tabular}{|l|c|}
\hline Intelligence & \\
\hline Linguistic & $\begin{array}{c}\text { Academic Intelligences } \\
\text { Logical/mathematical }\end{array}$ \\
\cline { 1 - 2 }
\end{tabular}




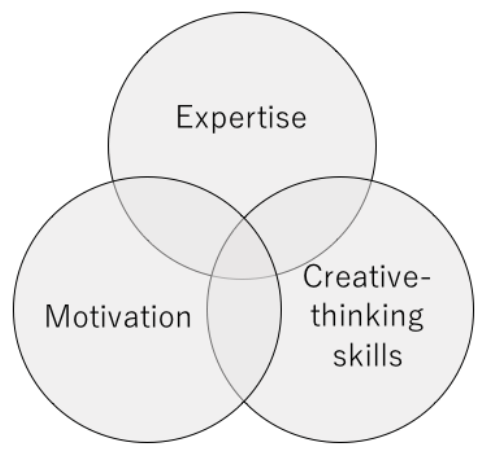

Fig. 1 Three Components of Creativity

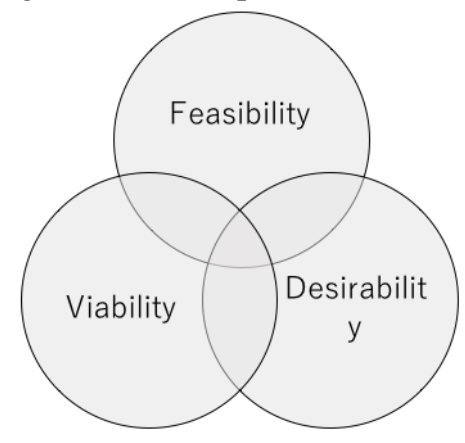

Fig. 2 Three Elements of Innovation

\section{CONCLUSIONS}

The conditions and issues of STEM education are different between the U.S. and Asia. Accordingly, the objectives and approaches of STEM education reforms are also different. Whereas the U.S. suffers from the low performance of students, Asia is concerned with the lack of engagement among students. The condition of secondary education is a serious issue in the U.S. The improvement of entrance examination system is critical in Asia.

Nevertheless, the improvement of STEM teaching is a common theme in the two regions to secure STEM workforce and to produce innovation. For this purpose, active learning plays a great role. The introduction of active learning is also justified from a perspective of the knowledge society which values creativity and innovation.

\section{REFERENCES}

[1] President's Council of Advisors on Science and Technology, Engage to Excel: Producing One Million Additional College Graduates With Degrees in Science, Technology, Engineering, and Mathematics, 2012, 1 .
[2] Gordon H. Hanson and Matthew J. Slaughter, "Talent, Immigration, and U.S. Economic Competitiveness, " 2013.

[3] Ethel Machi, "Improving U.S. Competitiveness with K-12 Education and Training," The Heritage Foundation, 2008.

[4] Association of American Colleges and Universities, Achieving Systematic Change: A Sourcebook for Advancing and Funding Undergraduate STEM Education, 2014, 4.

[5] Georgetown Public Policy Institute, Recovery: Job Growth and Education Requirements Through 2020, 2013.

[6] National Science Foundation, Science and Engineering Indicators, appendix table 2-37, 2014.

[7] Ibid., table 2-8, 2014.

[8] PCAST, op. cit., 5.

[9] AAC\&U. op. cit., 2.

[10] NSF, op. cit., appendix table 2-33.

[11] AAC\&U, op. cit., 2.

[12] Kristen Wolfe, "Understanding the Careers of the Alumni of the MIT Mechanical Engineering Department," 2014.

[13] Lumina Foundation, "Closing the Skill Gap: Companies and Colleges Collaborating for Change," 2014.

[14] Stephen E. Bradforth and Emily R. Miller, "Improve Undergraduate Science Education," Nature, Vol. 523, No. 16, 2015, 282-284.

[15] Vincent Talanquer and John Pollard, "Let's Teach How We Think Instead of What We Know," Chemistry Education Research Practice, No. 11, 2010, 74-83.

[16] James Fairweather, "Linking Evidence and Promising Practices in Science, Technology, Engineering, and Mathematics (STEM) Undergraduate Education," The National Academies Research Council Board of Science Education, 2008.

[17] Scott Freeman, Sarah L. Eddy, Miles McDonough, Michelle K. Smith, Nnadozie Okoroafor, Hanna Jordt, and Mary Pat Weneroth, "Active Learning Increases Student Performance in Science, Engineering, and Mathematics," PNAS, Vol. 111, No. 23, 2014, 8410-8415.

[18] Massachusetts Institute of Technology, "Institute-wide Task Force on the Future of MIT Education: Final Report," 2014.

[19] TIMSS \& PIRLS International Study Center, TIMSS 2012 International Results in Science, TIMSS 2012 International Results in Mathematics, 2012.

[20] Australian Council of Learned Academies, STEM: Country Comparisons, 2013.

[21] Howard Gardner, Frames of Mind: The Theory of Multiple Intelligences, Basic Books, 1983.

[22] Douglas Thomas and John Seely Brown, A New Culture of Learning: Cultivating the Imagination for a World of Constant Change, 2011.

[23] Teresa Amabile, "How to Kill Creativity," Harvard Business Review, Vol. 76, No. 5, 1998, 76-87.

[24] Tim Brown, Change by Design: How Design Thinking Transforms Organizations and Inspires Innovation, HarperBusiness, 2009. 